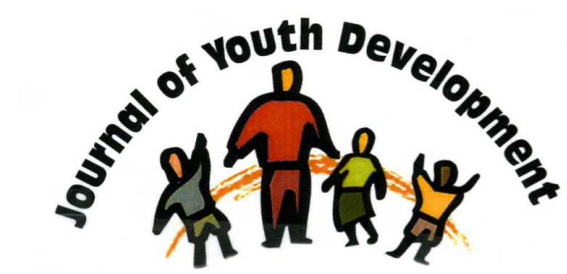

Bridging Research \& Practice

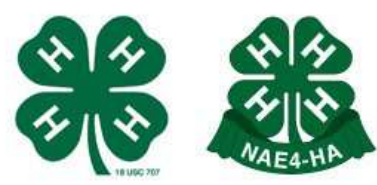

\title{
The After School Activity Initiative: Youth Helping Youth in a Community in Crisis
}

\author{
Brenda Robertson \\ School of Recreation Management \& Kinesiology \\ Acadia University \\ Wolfville, Nova Scotia \\ brenda.robertson@acadiau.ca
}




\title{
JOURNAL OF YOUTH DEVELOPMENT \\ bridging research and practice
}

\section{The After School Activity Initiative: Youth Helping Youth in a Community in Crisis}

\author{
Brenda J. Robertson \\ Acadia University
}

\begin{abstract}
Youth experience considerable free time, the use of which can foster active healthy lifestyles or facilitate engagement in activities that are detrimental to self and or to society. In order for the former to occur, specific knowledge, attitudes, and skills must be acquired. This research explores an initiative in which older youth served as leaders in an after school initiative in an economically challenged community where little attention was being paid to the provision of free time opportunities for youth. Not only were positive developmental outcomes experienced by the participants (the ability to find ways to spend free time; an appreciation for the outcomes that can accrue from engagement in positive activities; and the ability to communicate effectively), but the same was true for the older youth who served as leaders (understanding the meaning of success, appreciating the power of interpersonal relationships, and becoming a role model).
\end{abstract}

\section{Introduction}

The Carnegie Commission's report, A Matter of Time; Risk and Opportunity in the Non-School Hours (1992) shed light on the issue of how youth spend the $40 \%$ of their time that is discretionary. This time can be used to engage in recreation pursuits that foster positive youth development or to engage in activities that are detrimental to themselves and or to their communities. Since the early 1990's considerable attention has been paid to this issue including the development of a myriad of programs for youth, particularly for those considered to be atrisk. In assessing the impact of after school programs being developed for youth in high risk environments, Witt and Baker (1997) called from programs to do more than simply provide after school child care by attempting to address specific risk factors.

Much has been written about the benefits that accrue from youth engaging in quality structured recreation-related programs during free time such as playing on a sports team, joining a youth group, or pursuing a hobby (Hansen, Larson, Dworkin, 2003). Positive youth development is 
known to occur through participation in quality recreation experiences led by trained professionals who serve as leaders. But what opportunity is there for positive youth development in a community experiencing high unemployment, low educational achievement levels, wide spread family dysfunction, and high rates of crime and domestic violence? In communities, where recreation opportunities are limited and resources scarce, access to quality adult leadership may be limited or in some cases non existent.

The After School Activity Initiative (ASAI) was conducted in an economically challenged community where elimination of traditional forms of resource-based employment have caused high rates of long term unemployment and a host of accompanying social problems. As adults in the area struggle to restructure their lives in order to survive, youth are challenged to find productive ways to occupy their free time. Without skills, opportunities, and community support many youth engage in negative behaviours, or are at-risk of doing so, in order to satisfy their needs. Lack of structured sports and recreation opportunities and limited familial involvement in facilitating activities; have left many youth to fend for themselves during their free time.

The quality of leadership and the nature of the adult-youth relationship are considered key factors in the success of after school programs (McLaughlin, 2000; Russell, \& Reisner, 2006). Upon conducting an in-depth investigation of 10 after school initiatives, Grossman, Price, Fellerath, Jucovy, Kotloff, Paley, and Walker (2002) found the quality of the leader to be the key success factor in the provision of quality programs that enable youth to make productive use of free time and reduce negative behavior. It is difficult to challenge the value of having caring adult role models serve as leaders in after school, or any type of youth programs, but what if no such individuals are available? This is of particular concern in communities where parents are preoccupied with their own problems and therefore not willing or able to serve as youth leaders.

The concept for the ASAI was to use the physical resources of the school after hours, and have older youth from the high school run recreation programs for the elementary school children considered to be most in need. The initiative was operated under the direction of an adult project manager who supervised the student leaders by providing some training, along with support, and encouragement. Teachers within the elementary school were invited to refer students to the program. A limited number of other students from the school were also allowed to participate. The high school students who served as leaders for the program were ones who had found ways to pursue active positive lifestyles within the community. These students all expressed interest to serve as leaders and were selected by the project coordinator in consultation with school officials. It was felt that these young leaders could serve as positive role models for the children in the program.

The purpose of the research was to investigate whether an after school program with older youth serving as leaders for younger ones could produce positive developmental outcomes. Although the leaders understood the study to be primarily of the younger youth, outcomes relative to their own development were also being investigated. Central to the study was an investigation of the outcomes that accrued from involvement in the program by both the youth and their youthful leaders.

The ASAI consisted of a wide range of activities designed to address the needs of youth. Some activities were focused on the development of basic physical activity skills. There were others 
that introduced participants to a specific sport and recreation skills which supported children in skill development. Certain activities were designed to foster the development of skills required for participation in sport and recreation activities such as teamwork, communication, creativity, and fair play.

Participants included 53 youth between the ages of 8-11 years. Half of the youth were referred to the program by teachers who had either experienced behavioural issues with the child and/or knew that they fit the characteristics of the target group. The remainder of participants expressed an interest in participating in the program. The program ran between October and May and participants were entitled to attend twice a week (either Monday/Wednesday or Tuesday/Thursday) for two hours. Each day approximately 27 youth and 4 leaders participated in the program. Sessions consisted of entire group activities as well as smaller group ones where each leader would work with the same 6-7 children thereby facilitating the development of leader-participant relationships.

The youth leaders themselves, with limited guidance but plenty of support from the project coordinator, developed and implemented their own lesson plans for each session. Following each session, they would prepare a report recording the activities that took place, any challenges that they encountered and how they were addressed, as well as their personal feelings about the day. The project coordinator held weekly meetings with the leadership team to debrief.

\section{Data Collection and Results}

The high school students who served as youth leaders prepared a report after each session in which they described the activities of the day along with their personal reflections relative to program outcomes. At the conclusion of the program leaders were asked to record their reflections on overall success of the program. No data were collected from participants immediately upon conclusion of the program as any true developmental affects would only be realized with the passage of time. Upon returning to school in September, participants were interviewed by the Project Coordinator to ascertain what, if any, impact had accrued from their participation in the program during the previous academic year.

In order to avoid any bias and stereotyping by leaders or participants, only the project coordinator was aware of which youth had been referred to the program and which ones had elected to participate. The coordinator had a counseling background with considerable experience in group processes and group dynamics. After working with all of the youth, it was her opinion that there were no appreciable differences between the referred youth and the others and she considered all participants to be at-risk given the nature of the social environment of the community in which they resided.

\section{Participant Perspective}

Results indicated that children were very satisfied with their experience in the program. They identified specific activities, interacting with the leaders, and being with their friends as aspects of the program they most enjoyed. During follow up interviews, participants were asked what, if anything, they had learned as a result of being in the program the previous year. They identified the following as being most important:

- new activities to do in their free time (58\%), 
- how to improve certain activity skills (23\%),

- how to get along better with people (23\%), and

- the importance of being respectful of others (23\%).

Other behaviours reported being learned by $20 \%$ or less included: how to interact with others without bullying, how to help others, how to pay attention and listen, how to share, how to cooperate, and how to behave in ways that are appropriate.

Youth were asked what changes if any had resulted from them having been in the program. The most frequently cited responses were:

- could now think of things to do when they were bored (42\%),

- were better able to get along well with people (outside family) $(23 \%)$,

- had improved sport and recreation skills (19\%) and

- were able to get along better with family members (12\%).

Other changes identified by ten percent of participants or less included: spending more time helping others, being better able to control temper, being more physically active, watching less television, being more kind to others, feeling in a better mood, and being more respectful.

\section{Youth Leader Perspective}

Project youth leaders were chosen because they were potential role models who pursued active positive leisure lifestyles. The experience of working with children with any type of behavioural issues was new to most of them. Many could not relate to these types of behaviours as their own experience as children of this age differed significantly. A review of the leader reflections posted at the conclusion of sessions during the initial 6-8 weeks illustrated considerable stress, frustration, and despair resulting from interactions with participants. In addition, the older youth demonstrated considerable lack of confidence in their abilities to serve as effective leaders for the younger youth. By mid program, the postings appeared more positive as leaders came to better understand the needs of their charges and were developing strategies to work more effectively with the children. At the conclusion of the program, youth leaders reported they felt that the program had met or exceeded the original objectives. All indicated that they had grown as people and developed as leaders as a result of their involvement with the program.

\section{Youth leader's observed outcomes for participants}

Throughout the duration of the program, leaders consistently expressed the belief that participants were not only enjoying the program but were reaping considerable benefit, even when the leaders were feeling very challenged and frustrated. Following are the outcomes reported throughout the data:

Attitude and behaviour change: The most frequently reported outcomes related to attitude and behavioural changes that leaders observed over time. Although there were numerous specific incidents of negative behaviour cited early in the program, all reported changes in behaviour were positive. The following are representative quotes by the youth leaders regarding changes that they observed in the children. Incidences of youth showing respect for leaders and for one another were cited most frequently, followed by an increase in positive attitudes and in activity levels. 
- I have noticed a huge behavioural change in many of the participants. They are more selfconfident, respectful, and active.

- Many of the children have become more outgoing.

- For one boy who would never listen, his listening skills have improved slightly. Although it seemed like a small change, it is the kind of change that this program is all about.

- Some of the girls wouldn't play hockey at first because they thought that it was for boys but once they saw how much fun it was, they finally decided to get involved and now are the first ones ready to play.

- I have noticed huge behavioural change in many of the participants. They are more confident, active, and respectful.

- These kids have learned how to listen to us and cooperate with each other to create an enjoyable experience for everyone.

- I am seeing many small changes in some of the kids. One girl has gained so much more confidence and spirit and has become more outspoken.

- The majority of participants are now participating with positive attitudes, and show respect for one another and to us as the leaders.

- As leaders, we are hearing a lot of positive feedback from parents, teachers, and even from participants themselves. I have seen drastic changes in the behaviour of certain youth while others are changing but more slowly.

Communication/Self expression: In early posting, leaders frequently commented on the inability of many youth to express themselves appropriately. Although not universal, a general observation was that boys were loud and outspoken while females were extremely shy and non communicative. During the first two months, leaders frequently reported the lack of appreciation for the program demonstrated by participants. Over time, marked changes were noted with regard to the ability of participant's to express themselves, including their gratitude for the work of the leaders.

- One of the girls has gained so much confidence and spirit and now feels safe saying whatever she feels.

- One child who is shy has started to communicate with me by computer and told me that because of learning about soccer in our program she is going to join a team this summer.

- I see the children connecting with their leaders more every day. They have opened up to us and told us more about many aspects of their lives. They also tell us that they care about us and that makes all the stress they have put us though worthwhile.

- It makes it worthwhile when a child makes a card for me in craft time experiencing his or her appreciation.

Making positive choices. The leaders appeared to be surprised that such poor decisions were being made by certain youth. It became apparent to them however that by facilitating the development of both decision making skills and positive attitudes, they were providing participants with tools that would enable them to make wise choices.

- The important thing is that we have helped children think about the choices that they make and the impact of their decisions. 
- It is certainly less likely that they will continue to engage in bad behaviours because they have developed skills and attitudes that give them different choices.

- I feel that these kids will make better choices but without opportunities like this program, others will continue to engage in negative activities.

Consequence for action: This was another of the most frequently acknowledged outcomes of the program. The connection between one's actions and resultant consequences did not appear to be well established in the minds of many participants. Through employing basic program operating procedures, leaders attempted to help the youth make the connection and to extend into other aspects of the participant's lives.

- Many of these children lack structure at home but learned it here. They are less likely to engage in negative behaviour because they learned that there are consequences for their actions.

- $\quad$ Through our activities they really seem to have learned that rules exist for a reason and what happens if they are not followed.

- $\quad$ These kids are gaining an appreciation for the fact that negative consequences result from negative actions.

- $\quad$ Some of the children now get that if they act positively they are encouraged rather than acting in a negative fashion and being yelled at.

- $\quad$ They have learned through us that there are real consequences for your actions and that applies in the community as much as it does in the gym.

- If they get turned onto a sport they like, and many have, they will want to play it at school and they now realize that they can not if they don't act appropriately.

Active-healthy lifestyles. A focus of the program is to assist participants to make positive change that will result in the pursuit of active positive lifestyles in a community (and within certain families) where there appears to be little regard for the overall wellness of the youth.

- $\quad$ The fact that they are here and active means they are not just watching TV or out getting into trouble.

- I would say that some of the children have become much more active in their lifestyles and have actually lost some weight.

- $\quad$ The children have become more active and more importantly, interested in being active.

- I have actually noticed weight loss in some of the children who were not active before.

- Some have adopted a more healthy lifestyle and realize that negative behaviours are not healthy.

Enjoyment: When dealing with high risk populations who face many challenges, the quest to foster positive developmental outcomes often overshadows the importance of letting kids just be kids and enjoy themselves. Fun is an outcome that is not valued as highly as others are yet, in the case of these children living in the type of environment that they do, where it is a rarity, fun is an honourable objective. 
In the early weeks of the program, leaders placed value on being in control and having the children act in a structured and disciplined fashion which for the children was not particularly fun. Once relationships were established and respect fostered, leaders were more comfortable in allowing children to engage in unstructured play activity and just have fun.

- $\quad$ To be honest, the best part of this whole experience for me is seeing first hand that these children are having fun and enjoying themselves.

- $\quad$ Now that I am able to just enjoy myself with the children and let them have fun, I don't feel stressed or anxious that they are not learning everything I want them to.

\section{Outcomes related to leader's experience}

The main focus of this initiative was to offer an after school program that would hopefully provide positive developmental outcomes for participants, many of whom were considered atrisk primarily from living in a high-risk environment. The initiative was also designed to assess the suitability of having older youth from the same community, serve as leaders. Although the leaders were not considered to be at-risk, this research also sought to ascertain whether positive developmental benefits would accrue from their involvement with the younger youth. Evidence suggests that the leaders grew a great deal, both as leaders and as people, as a result of their involvement with the initiative. The following themes emerged relative to the outcomes for leaders: a redefinition of how success in defined, appreciating the value of interpersonal relationships between leaders and participants, and coming to view themselves as role models.

Definition of success: The greatest knowledge that leaders took away from the experience seemed to relate to their definition of success. In the beginning, leaders had the expectation that as a result of the program, every participant would learn to pursue a positive healthy lifestyle. The leaders believed success for participants in this program being through the honing of a particular skill or skills that would then be pursued in place of negative behaviours. They envisioned a scenario where participants would pay strict attention to them while they demonstrated skills they had themselves developed. Much of the reported frustration in the early stages of the program occurred when that scenario did not play out as they had envisioned it. Over time, as they grew to better understand the nature of the participants and where they were coming from, their definitions of success changed drastically to better fit the reality of the situation.

- I used to get frustrated at times when every child did not get every point that I tried to make but now I realize that if some of them really get it that we are making progress

- $\quad$ These children were not perfect when they came to us and they still act inappropriately at times but far less so and that is progress.

- Children are showing up and in many cases wanting to come more often. Every hour they spend here is one less spent in front of the television or the computer.

- If we keep one kid out of trouble it has all been worth it and I know we have done that for many more than just one.

- If we can do this for even one kid it has been worthwhile. We have tried to have fun with the kids and at the same time instill positive morals.

Interpersonal connections: The leaders did not anticipate developing interpersonal relationships with participants. Whether this was due to their lack of experience as leaders or that they did not perceive that they would connect with youth who were at-risk, is not known. A frequently 
reported outcome of the experience was that the older youth did develop relationships with individual participants and discovered that it was through such that the positive benefits accrued for both the participants and themselves.

- $\quad$ The 45 minutes development sessions really help me to connect with each child on an individual basis. This type of interaction is just not possible in the whole group activities and it is where most of the learning occurs for the kids.

- $\quad$ Over time I am getting to know each child on a personal level. They are more comfortable talking about themselves with me and I am becoming more comfortable with them as a result. One told me that he has developed an interest in drawing and wants to take a cartooning class and I found that very satisfying.

- $\quad$ The important interaction with the children isn't playing games with them, it is getting them to trust you and have them sit and want to talk with you and discuss aspects of their lives.

- Each of the children have connected with the at least one leader and have opened themselves up and shared with us important aspects of their lives. To me, that is the most valuable aspect of this whole experience, for them and us.

- I used to think that we had to control the children but now see that we need to develop a relationship with them. Once that was established, the behavioural issues seem to vanish.

Role models: It was expected that the leaders would serve as role models for the youth. Most seemed to accept that role simply as a characteristic associated with being a leader while others struggled to understand exactly what being a role model meant and why they would be perceived as such.

- $\quad$ Although initially I did not see how we would be so, I think we have been positive role models by helping them think about what they want to be like when they get older.

- We were role models in a way because they know we grew up in the same community and didn't get into trouble and ended up like we did and so if they want to be like us they can, but they need to stay out of trouble.

\section{Discussion}

The developmental benefits of youth participation in positive recreation programs and activities such as organized sport, Scouts, $4-\mathrm{H}$, and Boys \& Girls clubs during free time have been well documented (Witt, \& Caldwell, 2005). Such programs are of particular value in environments where lack of positive opportunities and access to negative influences exist putting children and youth at-risk (Witt, \& Baker, 1997). However, there are communities where such opportunities are non-existent or where access may be limited owing to a variety of factors. This study explored whether, in an economically challenged community where few adults expressed interest in facilitating opportunities for youth, older youth could effectively lead an after school program that would facilitate positive developmental outcomes. Making use of school facilities, and with the guidance and support of a project coordinator, the leaders were able to foster positive outcomes, both for participants as well as for themselves. 


\section{Primary Participant Outcomes}

The primary outcomes from the perspective of participants included: the ability to find ways to spend their free time; an appreciation for the outcomes that can accrue from engagement in positive activities rather than negative ones; and the ability to communicate and interact more respectfully and effectively with others. Discovering ways to occupy time in a more selfsufficient and satisfying manner is hugely important in a community such as this where opportunities for positive engagement are limited yet potentially negative influencers abound. Such a community does not guarantee or even attempt to provide structured means through which positive youth development can occur. As such, empowering youth to be able to use free time in meaningful pro social ways, by providing attitude and skill acquisition and the ability to interact with others more effectively, is essential for their development.

\section{Youth Leader Findings}

Observations from the leaders support the nature of the development reported by participants. A number of additional key findings were identified by leaders relative to the experience of the children. One such finding was that the program afforded youth the opportunity to develop at their own pace and in their individual areas of need. Although initially, through their lack of experience, the young leaders had a prescribed lesson plan and envisioned all youth learning the same things at the same time, over time they realized that the program could mean different things for different children. The format, in particular the smaller group initiatives, enabled leaders to work more closely with children and play closer attention to individual needs, whether those needs related to attitude, communication, behaviour, respect, confidence, or skill development.

Approximately $40 \%$ of time for children is considered to be free or discretionary (Carnegie Corporation of New York, 1992). As such, youth have choices to make in terms of how they spend that time. The project coordinator, through her interaction with parents of participants, indicated that there appeared to be little parental influence, guidance, or support in terms of how the youth spend their free time. As such, participants perceived there to be little opportunity or choice in terms of how to spend that time which resulted either in boredom or negative behaviour. When choice did exist, participants appeared to have few, if any, decision making skills. The development of such skills was a frequently reported outcome of the program and participant data suggests that those new found skills were able to be implemented.

Closely linked with freedom of choice, is the concept that there are consequences for the choices made. Grasping this concept appeared to have a positive influence on the nature of choices that the younger youth were making, both during the program and afterwards. It was empowering for youth to realize that they could control certain negative outcomes from their actions by altering their behaviour. Until the program, there appeared to be a cognitive disconnect between actions and consequences. Once the connection was established, youth were better able to accept responsibility for their actions.

The youth leaders had all experienced first hand, the benefits of leading active healthy lifestyles and expressed the desire to model that to the younger youth. It was not surprising therefore that one of the most rewarding outcomes witnessed by leaders was that of youth making decisions that positively affected their lifestyles. Seeing participants losing weight, watching less 
television, pursuing new interests, and generally being more active and enjoying themselves was very satisfying for leaders. Participants appeared to have gained awareness that although there were certain aspects of their lives that they could control, there were other aspects that were not necessarily in their control. There was recognition by leaders however that having knowledge of the benefits associated with an active healthy lifestyle would serve youth well in the future as they gained greater control over various aspects of their lives.

A unique aspect of this initiative was that although the leaders were youth who had grown up in the same community as participants, their experience had been very different. The older youth had been fortunate to have family and other adults who helped foster interest in particular pursuits at which they excelled. Their leisure pursuits served as a buffer to the negative influences in the community, a fact that the leaders grew to appreciate throughout the project. Their involvement in the after school initiative afforded them the opportunity to pass on, to the younger less fortunate youth, their knowledge and experience.

\section{Data Themes}

There were three dominant themes in data relative to positive outcomes experienced by the leaders themselves, in addition to the positive affect of having faced and overcome challenges as young leaders that resulted in being able to give of themselves to the participants with positive results. The themes included: gaining a better understanding the meaning of success, developing an appreciation for the value and power of interpersonal relationships, and recognizing that they had something worthy of being considered a role model.

Learning to appreciate that opinions differ in terms of definitions of success is something that will benefit these young leaders as they work and interact with people throughout their lives. Awareness that success can be realized and celebrated through small actions and not necessarily grand ones is an important life lesson. The ability to interact closely with others different from themselves, and to see positive results occur as a result that would not have otherwise, was another key outcome for the leaders. As role models, leaders felt they had something to offers younger youth based upon their success in their selected areas of leisure pursuit, be that though sport, music, drama, or other areas in which they excelled. What they came to realize was that it was not those factors that were so defining in terms of their personal identities that made them role models, but rather that they had found ways to cope with life's challenges. This was a gift that they were in a position to now give to the youth who looked up to them.

\section{Conclusions and Implications}

Few would argue that there are many factors in society today that serve to put youth at-risk. At no time in recent history has the need for positive youth development been as strong as it is today. While many youth are experiencing crisis related to their use of free time, adults are also facing challenges brought about by changing social and economic factors. Many adults find that they have neither the time to spend serving as leisure educators for their children or to volunteer as youth leaders within their communities. At the same time, current research in psychology suggests that prior methods of adults controlling and directing youth learning processes are not necessarily always effective. Youth development approaches where adults support experiential learning through which youth acquire skills by adult input more so than 
direction are also very effective (Ryan, \& Deci, 2003). Yet such approaches are more time consuming than simply imparting information to youth using structured adult-centered approaches. As a result, more youth are finding themselves at-risk of not reaping the benefits associated with recreation activity. Clearly within the current framework of societal pressure and challenge, new avenues for youth to access the developmental benefits associated with positive use of free time, possibly with less dependence on adult resources, must be found. The finding from this study offers just such an approach.

These finding indicate that both the participants and their youth leaders experienced positive outcomes, from a developmental perspective, as a result of their involvement with this initiative. What does appear clear is that older youth can effectively serve as leaders of their younger peers. These results suggest that peer leaders can facilitate the obtainment of positive developmental outcomes, similar to those reported in the literature attributable to having caring professional adult leadership (Grossman, Price, Fellerath, Jucovy, Kotloff, Paley, \& Walker, 2002).

There are three implications of this work for schools and other community youth serving agencies.

1. Youth need to learn certain knowledge, attitudes and skills in order to be relatively self-sufficient in terms of finding meaningful pro social ways to spend their free time;

2. With guidance and support, older youth can and should be considered as leaders for their younger peers. There are important developmental outcomes to be accrued by both sets of youth. For younger youth, they stand to gain valuable skills and attitudes essential to cope with the stresses of childhood, especially when growing up in a resource poor economically-challenged environment. For the leaders, they can gain important skills and attitudes that will assist with the difficult transition to adulthood.

3. Often youth are viewed as liabilities to communities rather than as assets or as having assts. In communities, particularly those that are resource poor and economicallychallenged, consideration should be given to what assets youth actually do possess and by what means can they be developed, keeping in mind the wellbeing of both the community and the youth themselves.

\section{References}

Carnegie Corporation of New York. (1992). A matter of time: Risk and opportunities in non school hours. NY: Carnegie Corporation of New York.

Grossman, J.B., Price, M.L., Fellerath, V., Jucovy, L.Z., Kotloff, L.J., Paley, R., et al. (2002). Multiple choices after school: Findings from the extended-service after schools initiatives. Philadelphia, PA: Public/Private Ventures.

Hansen, D.M., Larson, R.W., Dworkin, J.B. (2003). What adolescents learn in organized activities: A survey of self-reported developmental experiences. Journal of Research on Adolescents, 13(1), 25-55. 
McLaughlin, M.W. (2000). Community counts: How youth organizations matter for youth development. Washington, DC: Public Education Network.

Russell, C.A., \& Reisner, E.R. (2006). Supporting Social and Cognitive Growth Among Disadvantaged Middle-Grades Students in TASC After-School Projects. Journal of Youth Development. 1(2).

Ryan, R.M., \& Deci, E.L. (2003). On assimilating identities to the self: A self-determination theory perspective on internalization and integrity within cultures. In M.R. Leary \& J.P. Tangney (Eds.), Handbook of self and identity (pp. 253-272). New York: Guilford Press.

Witt, P.A., \& Baker, D.A. (1997). Developing after-school programs for youth in high risk environments. Journal of Physical Education, Recreation and Dance. 68(9), 18-20.

Witt, P.A., \& Caldwell, L.L. (2005). Recreation and Youth Development. State College, PA: Venture Publishing.

(C) Copyright of Journal of Youth Development Bridging Research and Practice. Content may not be copied or emailed to multiple sites or posted to a listserv without copyright holder's express written permission. Contact Editor at: patricia.dawson@oregonstate.edu for details. However, users may print, download or email articles for individual use.

ISSN 2325-4009 (Print); ISSN 2325-4017 (Online) 